\title{
PREVALENCE OF REFRACTIVE ERROR AND STRABISMUS IN PRIMARY SCHOOL CHILDREN OF TEHSIL LAKKI MARWAT, KHYBER PAKHTUNKHWA PAKISTAN
}

\author{
Faheem Ullah ${ }^{1}$, Naheed Mahsood ${ }^{2}$, Waqas Mohyuddin $^{3}$, Saadullah Afridi $^{4}$, Zia Ur Rehman $^{5}$
}

\section{ABSTRACT:}

\section{OBJECTIVES:}

Refractive errors and strabismus continue to remain a significant public health problem. Among school children it has an impact on child development. The aim of the study was to determine the prevalence and pattern of refractive error and strabismus among primary school children.

\section{METHODOLOGY:}

It was a cross-sectional study. Stratified random sampling technique was used to select the school children. Data was collected in November-December 2013. Visual impairment was defined as, presenting VA of $<6 / 12$. A total of 2288 children (1746 boys and 542 girls) were screened from 26 randomly selected schools. Stratified sampling technique was used. Data were collected on predesigned questionnaires and entered and analyzed by SPSS software version 16.

\section{RESULTS:}

The mean age of children was $8.10+2.3$ years. About $4 \%$ children were found visually impaired. The prevalence of refractive error was found to be $5.4 \%$, of which $88.6 \%$ was uncorrected refractive error. The prevalence of refractive error was found higher in girls than boys, $6.8 \%$ and $5.0 \%$ respectively. Among types of refractive error, myopia prevalence was $2.3 \%$, hypermetropia prevalence was $2.0 \%$ and astigmatism prevalence was $1.1 \%$. The prevalence of strabismus was $1.3 \%$. Refractive error was found as a main cause of visual impairment in school children. Prevalence of strabismus among this study population is relatively low as compared to the global prevalence of $2 \%$ to $5 \%$.

\section{CONCLUSION:}

It is recommended that more study to determine the extent of the problem and possible factors for development of refractive error and strabismus types are needed to mitigate these conditions.

KEYWORDS: Refractive Error, Strabismus, Visual Impairment, School Children

How to cite this article:

Ullah F, Mahsood N, Mohyuddin W, Afridi S, Rehman UZ. Prevalence of Refractive Error and Strabismus in Primary School Children of Tehsil Lakki Marwat, Khyber Pakhtunkhwa Pakistan. J Gandhara Med Dent Sci. 2020; 7(1): 11-21 


\section{Correspondence}

${ }^{1}$ Faheem Ullah, Mph Scholar, Khyber

Medical University, Peshawar. Peshawar

Cell\# +92-333-9112885.

Email: hamidhussain22@hotmail.com

${ }^{2}$ Assistant Professor, Khyber girls Medical

College, Peshawar.

${ }^{3}$ Khyber Medical University, Peshawar.

${ }^{4}$ Associate Professor, Sarhad Institute of

Health Sciences, Peshawar.

${ }^{5}$ Zia Ur Rehman: Assistant Professor,

Jinnah Medical College, Peshawar.

\section{INTRODUCTION:}

Visual impairment continues to remain a significant public health problem worldwide. The uncorrected refractive error has been considered one of the priorities of the WHO global initiative for the elimination of avoidable blindness ${ }^{1}$. About $80 \%$ of the visual impairment is avoidable ${ }^{2}$. One study reports that strabismus is the third most common ocular disorder in children of Pakistan ${ }^{3}$. School children are one of the key population groups that are most suffered by refractive error and strabismus. As children usually don"t complain of visual problems, early diagnosis and prompt treatment of visual impairing eye conditions is important to prevent the visual problems, which may affect child learning ability ${ }^{4}$. Our objectives were to determine the prevalence and pattern of refractive errors and strabismus among primary school children.

\section{METHODOLOGY:}

A cross sectional study was designed to assess the prevalence and pattern of presentation of refractive error and strabismus in school children aged 5 to 12 years in Lakki Marwat tehsil, Khyber Pakhtunkhwa Pakistan. There are total 666 primary schools in tehsil Lakki Marwat of which 447 are boys" schools and 219 are girls" schools. The total strength of children in these schools are 53082, of which 40507 are boys and 12575 are girls. A total of 26 primary schools ( 17 boys and 9 girls) were visited and 2288 children, of which 1746 were boys and 542 were girls, were screened. The study was conducted from August 2013 to January 2014 by stratified random sampling technique. All the government primary schools of tehsil Lakki Marwat were stratified into two strata i.e. boys and girls. Then required numbers of schools were randomly selected. To estimate the refractive error and strabismus prevalence of $05 \% 15$, with $95 \%$ confidence interval (4\% - 6\%) among school children having total strength of 53082; a sample size of 1485 is needed; and calculated as $60, \mathrm{n}=\mathrm{Z}_{\mathrm{\alpha} / 2}{ }^{2}$ (1-P) (P) $N / d^{2}(N-1)+Z_{\alpha / 2}{ }^{2} P(1-P)$. By adjusting for the design effect of 1.4 and non-compliance of $10 \%$ the final sample size calculated was 2288 . A medical team consisting of optometrist and technicians carried out the data collection. Ethical approval was obtained from the ethical approval committee of Khyber Medical University and permission was taken from concerned district education officers. Dates were fixed 
for screening of each school and all the concerned headmasters" presence was ensured. Children personal data and eye examinations data was recorded using predesigned RESC Eye Examination form of WHO. In each school an appropriate room was selected for examination, which was properly illuminated. Children who were already wearing glasses, their presenting VA were assessed (while wearing their glasses). All ocular alignment assessments were performed without spectacles. Initially ocular alignment was determined using corneal reflections (Hirschberg Test), followed by a cover/uncover test using an occlude and performed at 0.5 and 4 meters. Children, whose vision was improving with refractive correction, were prescribed glasses. A child needing diagnostic workup or surgical treatment was referred to the concerned hospital. Proper informed written consent was obtained from the parents of all children through concerned head teachers. Descriptive statistics such as frequencies, percentages, means and standard deviations were used.

\section{RESULTS:}

The study population was comprised of $1746(76.3 \%)$ boys and $542(23.7 \%)$ girls. Among study population, 2196 (96\%) children were found normal or no visual impairment, 54 (2.4\%) children were mild visually impaired, $23(1 \%)$ were moderate visually impaired, 8 $(0.3 \%)$ were severe visually impaired and $7(0.3 \%)$ were blind. The overall prevalence of presenting visual impairment in study population was $4 \%$ (95\% Cl $3.21 \%$ to $4.79 \%)$. Prevalence of presenting visual impairment was observed to be higher in girls $(5.4 \%)$ as compared to boys $(3.7 \%)$. Figure 1 shows the type of visual impairment in study population. Reasons for presenting VA $\leq 6 / 12$ or 0.3 Log MAR in better eye (visual impairment) were found to be due to refractive error 49 $(53.3 \%)$, amblyopia $33(35.9 \%)$, corneal opacities/disorders 7 (7.6\%), and posterior segment disorders $3(3.3 \%)$.

Figure 1: Causes of Presenting Visual Impairment

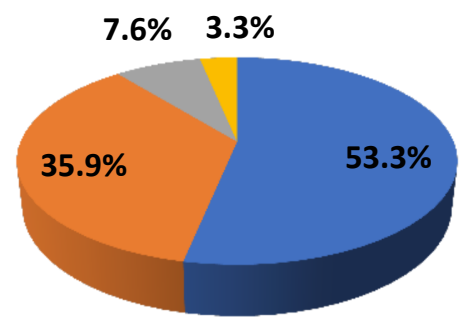

Refractive errors

Amblyopia

- Corneal opacities/disorders

Posterior segment disorders

Table1: Causes of Presenting Visual Impairment in Study Population by Gender 


\begin{tabular}{|l|c|c|c|c|c|}
\hline Gender & $\begin{array}{c}\text { Refractive } \\
\text { Error }\end{array}$ & Amblyopia & $\begin{array}{c}\text { Corneal } \\
\text { Disorders }\end{array}$ & $\begin{array}{c}\text { Posterior } \\
\text { Segment } \\
\text { Disorders }\end{array}$ & Total \\
\hline Boys & $28(45.9 \%)$ & $28(45.9 \%)$ & $4(6.6 \%)$ & $1(1.6 \%)$ & $61(100 \%)$ \\
\hline Girls & $21(67.7 \%)$ & $05(16.1 \%)$ & $3(9.7 \%)$ & $2(6.5 \%)$ & $31(100 \%)$ \\
\hline Total & $49(53.3 \%)$ & $33(35.9 \%)$ & $7(7.6 \%)$ & $3(3.3 \%)$ & $92(100 \%)$ \\
\hline
\end{tabular}

The overall prevalence of refractive error was found to be $5.4 \%$ i.e. 123 refractive error cases in 2288 children $(95 \% \mathrm{Cl} 4.49 \%$ to $6.31 \%)$. The prevalence of refractive error was found higher in girls than boys, $6.8 \%$ (37 case in 542 ) and $5.0 \%$ (86 cases in 1746) respectively.

Figure 2: Prevalence of Refractive Error in Study Population

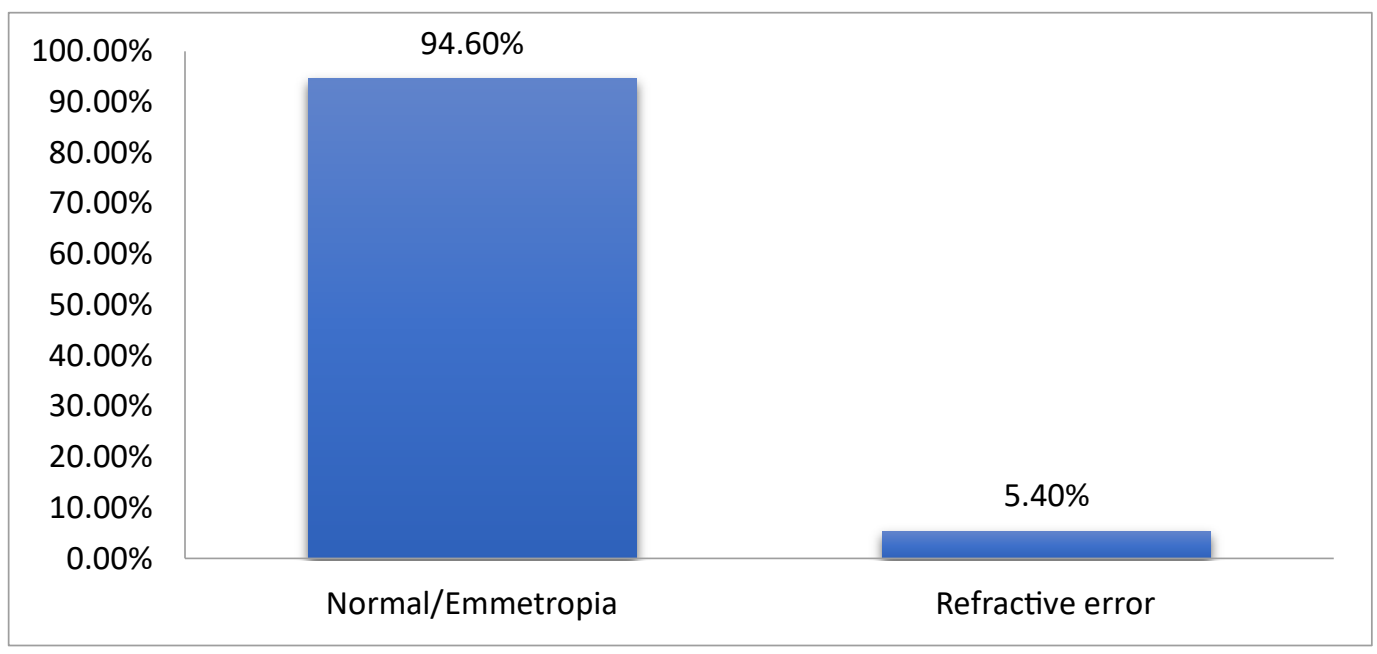

Table 2: Prevalence of Refractive Error in Study Population by Gender

\begin{tabular}{|l|c|c|c|}
\hline \multicolumn{1}{|c|}{ Gender } & $\begin{array}{c}\text { Number of } \\
\text { Children }\end{array}$ & $\begin{array}{c}\text { Refractive Error } \\
\text { Cases }\end{array}$ & Prevalence (\%) \\
\hline Boys & 1746 & 86 & $5.0 \%$ \\
\hline Girls & 542 & 37 & $5.8 \%$ \\
\hline Total & 2288 & 123 & $5.4 \%$ \\
\hline
\end{tabular}

The number of refractive error cases newly detected (uncorrected refractive error) and children who were already wearing spectacles 
(corrected refractive error). In this study $109(88.6 \%)$ new cases of refractive error were found, and 14 $(11.4 \%)$ children were already wearing spectacles out of 2288 children screened.

In this study myopia was found the most common type of refractive error, 51 $(41.5 \%)$ children out of 123 children were myopic (with girls shared more than boys $51.4 \%$ and $36.4 \%$ respectively). Hypermetropia was the second common type of refractive error. $47(35 \%)$ children out of 123 children were hypermetropia (with boys contributed more than girls $43.2 \%$ and $24.3 \%$ respectively). Astigmatism was found as the least common type of refractive error. $25(23.5 \%)$ children out of 123 children were suffering from astigmatism.

Table 3: Prevalence of Different Types of REs in Study Population by Gender

\begin{tabular}{|l|c|c|c|c|c|c|c|}
\hline Gender & No of & \multicolumn{2}{|l}{ Types Of } & Refractive & Errors \\
& \multirow{2}{*}{ Children } & \multicolumn{2}{|l|}{ Myopia } & \multicolumn{2}{l|}{ Hypermetropia } & \multicolumn{2}{l|}{ Astigmatism } \\
\cline { 3 - 8 } & & Cases & $\%$ & Cases & $\%$ & Cases & $\%$ \\
\hline & & 32 & $1.8 \%$ & 38 & $2.2 \%$ & 16 & $0.9 \%$ \\
\hline Boys & 1746 & 19 & $3.5 \%$ & 9 & $1.7 \%$ & 9 & $1.7 \%$ \\
\hline Girls & 542 & 51 & $2.3 \%$ & 47 & $2.0 \%$ & 25 & $1.1 \%$ \\
\hline Total & 2288 & $51 \%$ & & & & & \\
\hline
\end{tabular}

In this study the prevalence of strabismus was observed to be $1.3 \%$ i.e. 29 strabismus cases in 2288 children $(95 \% \mathrm{Cl} 0.85 \%$ to $1.75 \%)$. No significant difference in prevalence of strabismus was found between boys (1.3\%) and girls $(1.3 \%)$. 
Figure 3: Prevalence of Strabismus in Study Population

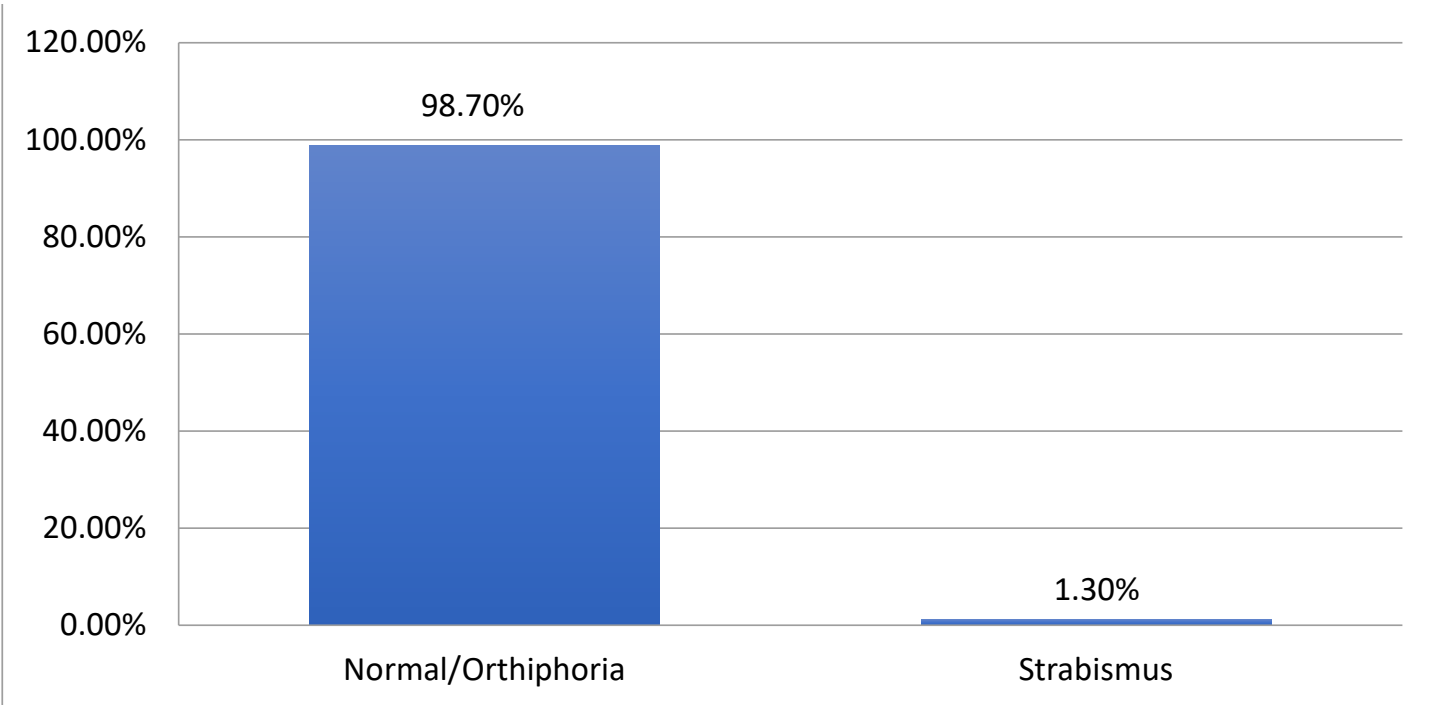

Table 4: Prevalence of Strabismus by Gender

\begin{tabular}{|l|c|c|c|}
\hline \multicolumn{1}{|c|}{ Gender } & Number of Children & Strabismus Cases & Prevalence (\%) \\
\hline Boys & 1746 & 22 & $1.3 \%$ \\
\hline Girls & 542 & 7 & $1.3 \%$ \\
\hline Total & 2288 & 29 & $1.3 \%$ \\
\hline
\end{tabular}

\section{DISCUSSION:}

Childhood blindness and uncorrected refractive errors are among the five priorities targeted in VISION-2020. Visual experience of a child plays a major role in their psychological, physical and intellectual development. Visual impairment due to uncorrected refractive error and strabismus can have both short and long-term consequences in children ${ }^{5}, 6$. According to the Baltussen et al, screenings of 5-15 years old children yields the most cost-effective health effects $^{7}$. In this cross-sectional, schools-based prevalence study of refractive error and strabismus in primary school children of tehsil Lakki Marwat, total 2288 children aged from 5-12 years old were screened. In this study no significant difference was observed between mean ages of boys (8 years) and girls (8.2 years). The mean age agreed with AlWadaani FA et $\mathrm{al}^{8}$. The overall prevalence of presenting visual impairment in this study was $4.0 \%$. This is like Kumah BD et al in Ghana, where the prevalence of presenting visual impairment in school children was $3.5 \%$. However, Casson RJ et al in Lao People's Democratic Republic 
observed low prevalence of presenting visual impairment at $1.9 \%{ }^{10}$. While study in China, had a prevalence of $6.64 \%$ of presenting visual impairment ${ }^{11}$. Like RESC study, ${ }^{12}$ refractive errors was the prime cause of visual impairment in our study and were responsible for most of the cases $(53.3 \%)$ of visual impairment. It is interesting to note that in our present study amblyopia was accountable for $35.9 \%$. A study in Ghana, observed that amblyopia accounted for $9.9 \%$ visual impairment $^{9}$. The high contribution of amblyopia to visual impairment in our present study may be due to high number of uncorrected refractive error cases $(88.6 \%$ of the total refractive error cases) in our study; as uncorrected refractive errors are the major cause of amblyopia. In our study prevalence of refractive errors among study population was found to be $5.4 \%$, which falls within the World Health Organization prevalence of 2$10 \%$ globally ${ }^{13}$. This is also comparable to the prevalence observed by Gao $Z$ et al in Cambodia $(6.57 \%)^{14}$, and by Pavithra $M$ et al in India $(7.03 \%)^{15}$. However, this is higher than the prevalence reported by Shaikh and Aziz in South Karachi $(2.0 \%)^{3}$, Opubiri and Pedro-Egbe in Nigeria $(2.17 \%)^{13}$, and Casson RJ et al in Lao People's Democratic Republic $(3.6 \%)^{10}$. On the other hand, the refractive error prevalence in our study is much less than the other similar studies conducted in Turkey $(23.4 \%)$ by Caca I et $\mathrm{al}^{16}$, in Iran $(22.66 \%)$ by Yekta $\mathrm{A}$ et $\mathrm{al}^{17}$ and in Saudi Arabia (13.7\%) by Al-Wadaani FA et $\mathrm{al}^{8}$. These studies specify that the prevalence of refractive errors is much higher than our results. Although these studies had used almost same case definitions and methods as used by us, but wide variations of refractive errors prevalence observed by different authors are naturally likely to be due to differences in sample sizes, age, geographical situation, ethnic variation and nutritional status. Refractive error was found more prevalent in girls $(6.8 \%)$ compared to boys $(5.0 \%)$. Similar results were found by Alam $\mathrm{H}$ et al in their study on school children in Karachi, where it was reported that prevalence of refractive error was $8.9 \%$ in female children, while no single case of refractive error was found in male children ${ }^{18}$. Another study in India by Sharma $S$ et al found that refractive error prevalence was $23.7 \%$ in girls and $12.2 \%$ in boys $^{19}$. While some studies reported higher prevalence of refractive error in boys than girls. Study by Soomro MZ et al in Southern Punjab found that prevalence of refractive error was $19.1 \%$ in boys and $16.1 \%$ in girls ${ }^{20}$. We have found a higher prevalence of myopia $(2.3 \%)$ in our study than that of hyperopia $(2.0 \%)$ and astigmatism $(1.1 \%)$. In India myopia was more prevalent $(3.16 \%)$ than hypermetropia $(1.06 \%)$ and astigmatism $(0.16 \%)^{21}$. Among all types of refractive errors, myopia was $41.5 \%$, which is consistent with other studies done in Pakistan by Ali $\mathrm{A}$ et al in Lahore (myopia 43\%) 22 and Soomro MZ et al in Southern Punjab $(\text { myopia } 58.23 \%)^{20}$. In our present study we have observed high 
prevalence of myopia and astigmatism in girls. Also found that the myopia prevalence significantly increased with age, while no significant difference in prevalence of astigmatism was found with age. Whereas, the prevalence of hypermetropia was observed significantly higher in the boys and younger age children. This trend may be attributed to the theory of emmetropization in which there is a shift from hyperopia in early childhood to emmetropia as the child grows. Caca I et al, in their study also found that myopia was associated with older age and females, whereas hypermetropia was inversely proportional to the old age ${ }^{16}$. Similar study by Czepita D et al, in Poland found a positive correlation between prevalence of myopia and age, as well as negative correlation between prevalence of hypermetropia and age, while no association was observed between the prevalence of astigmatism and age ${ }^{23}$. According to the literature review, all data available in Pakistan on strabismus is hospital based. No proper study was found, on prevalence of strabismus in school children. In present study we have determined the status of strabismus in school children. Although the prevalence of strabismus in our study was not as considerable like refractive errors, it requires prompt intervention since the affected children are prone to amblyopia, binocular problems and cosmeticrelated psychological disturbances. The prevalence of strabismus in our study was $1.3 \%$. This is comparable with the results of study in Japan, where Matsuo $\mathrm{T}$ et al, reported the prevalence of strabismus as $1.28 \%{ }^{24}$. However this prevalence is relatively lower than the global prevalence of strabismus (2 to $5 \%)^{25}$, and also from other studies conducted by Faghihi $\mathrm{M}$ et al in Iran $(3.1 \%)^{26}$, Bansal A et al in India $(3.92 \%)^{27}$, and Lin $S$ et al in China $(10.9 \%)^{28}$. Whereas Sherpa D et al reported low prevalence in Nepal $^{29}$.

\section{CONCLUSION:}

We concluded that the school going children is a high-risk group for developing refractive errors and strabismus. Refractive error was found as a main cause of visual impairment in school children and contributed to more than half of the visual impairment. Although the prevalence of strabismus in our study was not as considerable as refractive errors, it requires prompt intervention since the affected children are prone to amblyopia, binocular problems and cosmetic-related psychological disturbances. It is suggested that screening programs need to be implemented on a large scale to make possible early detection of vision impairing conditions in school children. Also, in this study it was found that the myopia and exotropia prevalence significantly increased with age, while hyperopia and esotropia prevalence was observed to decline with age. Studies are needed to determine the possible risk factors responsible for different types of refractive errors and strabismus development. It is recommended that more studies to determine the risk 
factors, control it so that to achieve the goal of Vision 2020.

\section{LIMITATIONS:}

Due to limited time and resources, this study focused only on schools within one tehsil of district Lakki Marwat, therefore limiting findings to a tehsil Lakki Marwat. Another limitation is that strabismus was measured only as present or absent through Hirschberg corneal reflex test and cover test. Prism testing was not performed. Also, the possible risk factors responsible for different types of refractive errors and strabismus development were not possible to study due to difficulties inherent with the used research design.

\section{REFERENCES:}

1. World Health Organization. State of the world,,s sight: VISION 2020: the Right to Sight: 1999-2005. World Health Organization; 2005.

2. World Health Organization. Visual impairment \& blindness: Factsheet No 282. World Health Organization; 2013.

3. Shaikh SP, Aziz TM. Pattern of eye diseases in children of 5-15 years at Bazzertaline area (South Karachi), Pakistan. J Coll Physicians Surg Pak. 2005;15:291-4.

4. Planning and Development (P\&D) Department. Khyber PakhtunkhwaSouthern Area Development Project (KP-SADP): Environmental and Social Assessment [Online]. Government of Khyber Pakhtunkhwa Civil Secretariat- Peshawar; 2012.

5. Resnikoff S, Pascolini D, Mariotti SP, Pokharel GP. Global magnitude of visual impairment caused by uncorrected refractive errors in 2004.

Bull World Health Organ. 2008;86(1):63-70.

6. Mojon-Azzi SM, Mojon DS. Opinion of headhunters about the ability of strabismic subjects to obtain employment. Ophthalmologica. 2007;221:430-3.

7. Baltussen R, Naus J, Limburg $\mathrm{H}$. Cost-effectiveness of screening and correcting refractive errors in school children in Africa, Asia, America and Europe. Health Policy. 2009;89(2):201-15.

8. Al Wadaani FA, Amin TT, Ali A, Khan AR. Prevalence and pattern of refractive errors among primary school children in Al Hassa, Saudi Arabia. Global J Health Sci. 2013;5(1):125-34.

9. Kumah BD, Ebri A, Abdul-Kabir M, Ahmed AS, Koomson NY, Aikins S, et al. Refractive error and visual impairment in private school children in Ghana. Optom Vision

Sci. 2013;90(12):1456-61.

10. Casson RJ, Kahawita S, Kong A, Muecke J, Sisaleumsak $\mathrm{S}$, Visonnavong V. Exceptionally low prevalence of refractive error and visual impairment in school children from Lao People's Democratic Republic. Ophthalmology. 2012;119(10):2021-7.

11. Guo Y, Liu LJ, Xu L, Lv YY, Tang $P$, Feng $Y$, et al. Visual impairment and spectacle use in school children in rural and urban regions in Beijing. Eur $\mathrm{J}$ Ophthalmol. 2014;24(2):258-64.

12. Mehari ZA, Yimer AW. Prevalence of refractive errors among school children in rural central Ethiopia. Clin Exp Optom. 2013;96(1):65-9. 
13. Opubiri I, Pedro-Egbe CN. Screening of primary school children for refractive error in South-South Nigeria. Ethiop J Health Sci. 2012;22(2):129-34.

14. Gao Z, Meng N, Muecke J, Chan WO, Piseth $\mathrm{H}$, Kong $\mathrm{A}$, et al. Refractive error in school children in an urban and rural setting in Cambodia. Ophthalmic Epidemiol. 2012; 19(1):16-22.

15. Pavithra M, Maheshwaran R, Rani Sujatha MA. A study on the prevalence of refractive errors among school children of $7-15$ years age group in the field practice areas of a medical college in Bangalore. Int J Med Sci Public Health. 2013;2(3):641-5.

16. Caca I, Cingu AK, Sahin A, Ari $S$, Dursun ME, Dag U, et al. Amblyopia and refractive errors among schoolaged children with low socioeconomic status in southeastern Turkey. J Pediatr Ophthalmol Strabismus. 2013;50(1):3743.

17. Yekta A, Fotouhi A, Hashemi $\mathrm{H}$, Dehghani $\mathrm{C}$, Ostadimoghaddam $\mathrm{H}$, Heravian J, et al. Prevalence of refractive errors among schoolchildren in Shiraz, Iran. Clin Exp Ophthalmol. 2010;38(3):242-8.

18. Alam H, Siddiqui MI, Jafri SI, Khan AS, Ahmed SI, Jafar M. Prevalence of refractive error in school children of Karachi. J Pak Med Assoc. 2008;58(6):322-5.

19. Sharma S, Vashisht BM, Kalhan M, Goel M. Magnitude of refractive errors among school children in a rural block of Haryana. Internet J Epidemiol. 2009;6(2):1-5.

20. Soomro MZ, Riaz S, Arshad M, Halili MR. Prevalence of refractive error in school going children in Southern
Punjab (Pakistan). Ophthalmol Update. 2013;11(4):194-6.

21. Padhye AS, Khandekar $\mathrm{R}$, Dharmadhikari S, Dole K, Gogate $\mathrm{P}$, Deshpande M. Prevalence of uncorrected refractive error and other eye problems among urban and rural school children. Middle East Afr J Ophthalmol. 2009;16(2):69-74.

22. Ali A, Ahmad I, Ayub S. Prevalence of undetected refractive errors among school children. Biomedica. 2007;23:96101.

23. Czepita D, Mojsa A, Ustianowska M, Czepita M, Lachowicz E. Prevalence of refractive errors in school children ranging from 6 to 18 years of age. Ann Acad Med Stetin. 2007;53(1):53-6.

24. Matsuo T, Matsuo C. The prevalence of strabismus and amblyopia in Japanese elementary school children. Ophthalmic Epidemiol. 2005;12(1):31-6.

25. Iqbal S, Jehangir N, Ahmed M, Shah SA, Khalil MZ. Etiology of strabismus in Ophthalmology Department, Hayatabad Medical Complex, Peshawar Pakistan. Ophthalmol Update. 2012;10(1):34-6.

26. Faghihi M, Ostadimoghaddam $\mathrm{H}$, Yekta AA. Amblyopia and strabismus in Iranian school children, Mashhad. Strabismus. 2011;19(4):147-52.

27. Bansal A, Krishnappa K, Datti NP, Guroprrsad BS, Guha J. Ocular morbidity in school going children of Kolar district, South India. J Clin Biomed Sci. 2012;2(4):175-84.

28. Lin S, Zhang M, Huang Y, Qiu K, Chen B. Population prevalence and psychological correlates of strabismus among urban and rural school children in Southern China. Invest Ophthalmol Visual Sci. 2012;53(14):1760. 
29. Sherpa D, Panta CR, Joshi N. Ocular

Nepal. Nepal J morbidity among

primary school children of Dhulikhel,

Ophthalmol. 2011;3(2):172-6.

\section{CONTRIBUTORS}

1. Faheem Ullah - Concept \& Design; Final Approval

2. Naheed Mahsood - Data Acquisition; Data Analysis/Interpretation; Drafting Manuscript

3. Waqas Mohyuddin - Concept \& Design; Critical Revision

4. Saadullah Afridi - Data Analysis/Interpretation; Drafting Manuscript

5. Zia Ur Rehman - Data Acquisition; Supervision

COPYRIGHTS: Authors retain the rights without any restrictions to freely download, print, share and disseminate the article for any lawful

purpose. It includes scholarly networks such as Research Gate, Google Scholar, LinkedIn, Academia.edu, Twitter, and other academic or

professional networking sites 